\title{
Trabeculectomy in Nigerian patients with open-angle glaucoma
}

\author{
C. P. THOMMY AND I. S. BHAR \\ From the Guinness Ophthalmic Unit, Ahmadu Bello University Teaching Hospital, Kaduna, Nigeria
}

SUMMARY Filtering procedures for glaucoma in Africans are considered to be failures owing to their propensity for increased fibrosis. However, favourable results from trabeculectomy in African patients with glaucoma are reported. Most of these are from such modifications of technique as non-suturing of flaps, sclerectomy, posterior lip cautery, or administration of high doses of steroids. In this study $95.4 \%$ success with a virtual absence of complications is reported from a standard technique of trabeculectomy and no steroids.

Visual deficit and blindness resulting from glaucoma in Nigeria are considerable. Open-angle glaucoma is the commonest type encountered. Angle-closure glaucoma and acute congestive episodes are rare. Surgery for glaucoma forms $18 \%$ of all intraocular surgery at the Ophthalmic Unit of Ahmadu Bello University Teaching Hospital. This is because surgery is the only satisfactory method of treating the great majority of glaucoma patients here (Keitzman, 1976; Sandford-Smith, 1978).

Traditionally filtration procedures are considered to be ineffective in Africans wherever they may be, owing to a racial propensity to excessive scar formation (Welsh, 1970). So cyclodiathermy and cyclodialysis were preferred as the first procedures for African patients (Stocker, 1945; Becker, 1958). Because of the deep-rooted concept of filtration failure a trabeculectomy procedure has been modified to improve results in the African by such means as excising Tenon's capsule, non-suturing, loose suturing, or minimal suturing of the scleral flap (Welsh, 1972; Freedman et al., 1976; Keitzman, 1976; Fergusson and MacDonald, 1977; SandfordSmith, 1978), sclerectomy, iris inclusion (Welsh, 1972), cauterising the posterior lip and beyond (Schimek and Williamson, 1977). or adding a regimen of high doses of corticosteroids (Fergusson and MacDonald, 1977). Favourable results, however, have been reported from trabeculectomy without such measures (Chatterjee and Ansari, 1972; David et al., 1977).

Address for reprints: Dr C. P. Thommy, Guinness Ophthalmic Unit, Ahmadu Bello University Teaching Hospital, PMB 2016, Kaduna, Nigeria
In this paper we present high rates of success and virtual absence of complications from trabeculectomy without recourse to additional techniques or medical management in a wholly African group of patients with open-angle glaucoma in Nigeria. We describe certain aspects of the surgical techniques conducive to such favourable results.

\section{Material and methods}

Trabeculectomy was done in 139 eyes (104 bilaterally, 35 unilaterally) of 87 patients with open-angle glaucoma aged between 36 and 72 years. 111 eyes (44 males, 18 females) were followed up for a minimum period of 6 months and a maximum of 19 months. Their visual status ranged from perception of light (PL) or counting fingers (CF) to $6 / 6$ to $6 / 5$. Their intraocular pressures (IOP) ranged between 30 and $70 \mathrm{mmHg}$. The cup/disc ratio ranged from 0.6 to endstage cupping. Their fields corresponded largely with the disc changes. All patients were Nigerians and all were seen and operated on by the authors under general anaesthesia (except 4 which were done under sedation and local anaesthesia by registrars under close supervision by the authors) at the Guinness Ophthalmic Unit of Ahmadu Bello University Teaching Hospital, Kaduna, Nigeria.

Each patient was admitted the day before operation after diabetes, hypertension, or other systemic conditions had been brought under control by a physician. Antiglaucoma medication (pilocarpine $2 \%$ and/or epinephrine borate (Epinal 1\%) and/or acetazolamide (Diamox) was prescribed as indicated as soon as the diagnosis was made in the outpatient 
Table 1 Patients and eyes

\begin{tabular}{|c|c|c|c|c|c|c|c|c|c|}
\hline & \multicolumn{4}{|c|}{ Patients } & \multicolumn{2}{|l|}{ Age } & \multicolumn{3}{|l|}{ Eyes } \\
\hline & Total & Percentage & Male & Female & Minimum & Maximum & Total & $\begin{array}{l}\text { Bilateral } \\
\text { eyes/ } \\
\text { Patients }\end{array}$ & $\begin{array}{l}\text { Unilateral } \\
\text { eyes }\end{array}$ \\
\hline Operated & 87 & & & & & & 139 & $104 / 52$ & 35 \\
\hline Followed-up & 62 & $71 \cdot 3$ & 44 & 18 & 36 & 72 & 111 & $98 / 49$ & 13 \\
\hline
\end{tabular}

Table 2 Follow-up

\begin{tabular}{lll}
\hline Duration & Patients & Percentage \\
\hline 6 to 11 months & 33 & $53 \cdot 23$ \\
12 to 19 months & 29 & 46.77 \\
\hline
\end{tabular}

Table 3 Visual status of follow-up patients

\begin{tabular}{|c|c|c|c|}
\hline & Both eyes & One or both cyes & One or both eyes \\
\hline & PL/CF to $6 / 60$ & $6 / 36$ to $6 / 18$ & $6 / 12$ to $6 / 5$ \\
\hline Patients & 17 & 24 & 21 \\
\hline Percentage & $27 \cdot 42$ & $38 \cdot 71$ & $33 \cdot 87$ \\
\hline
\end{tabular}

department and was continued until and including the day of admission. The average duration of this period of medical management was 1 month.

No antiglaucoma medication was given on the day of operation, nor postoperatively unless there was any complication. No systemic corticosteroids were given before or after surgery. No subconjunctival depot steroid was given at surgery. Pilocarpine $2 \%$ drops were instilled immediately after iridectomy, followed by atropine $1 \%$ drops at the end of the operation. Steroid and atropine drops were regularly used from the first postoperative day, and continued for about 6 weeks or until all signs of inflammation subsided. If both eyes were affected, both sides were operated on at the same time. In all cases the excised piece of sclerocornea was examined histopathologically. Postoperatively there was no restriction of movements once the patient was out of anaesthesia. A daily inspection and dressing was routine.

A tonometry was done on the day of discharge (5th or 6th day) and on every visit (every week for 3 weeks, at the 6th week, monthly, and then every 3 months for 1 year, 6-monthly in the following year). Gonioscopy and functional status were reviewed at these visits.

TECHNIQUE

General anaesthesia (halothane, nitrous oxide, oxygen) was given in all cases except for 4 eyes done under local anaesthesia with sedation. A 2-5-times operating loupe was used for magnification, though an operating microscope was used to confirm landmarks and for teaching.

Generally Watson's (1972) modification of the trabeculectomy of Cairns (1969) as described by Galin et al. (1975) was used except as follows.

(a) Conjunctivo-Tenon's flap.-Tenon's layer was not excised. Two types of flaps were fashioned: (i) classical, large, limbal based, turned over the cornea (68 eyes); and (ii) semi-fornix-based triangular flap (43 eyes) (Figs. 1 and 2). The conjunctiva is incised and undermined at the limbus from 10.30 to 2 o'clock or less and cut posteriorly for 8 to $10 \mathrm{~mm}$ on one side, the position depending on a superomedial or superolateral trabeculectomy. The triangular flap is reflected away from the site of operation, giving excellent exposure. At the end of surgery this flap is drawn taut to hug the limbus firmly and anchored, the first suture taking a deep bite at the anterior end of the posterior directed incision; 1 or 2 additional sutures may be applied at the limbus or a continuous one. The excess of the flap may be excised and the incision closed by interrupted or continuous sutures, or brought down to be sutured to the original incision.

(b) Scleral site. An area superolateral or superomedial or central, devoid of large vessels, is chosen. This area is lightly heat-cauterised. No cautery is applied after the scleral incision is made.

(c) Size and thickness of superficial scleral flap. The size varied between 4.5 and $5.5 \mathrm{~mm}$ at the limbus and 4.5 and $5 \mathrm{~mm}$ posteriorly, depending on the site chosen; large vessels were avoided, particularly the perforating anterior ciliaries. The thickness was always more than two-thirds, leaving a thin bluish posterior layer. Anteriorly dissection extended about $1 \mathrm{~mm}$ into clear cornea to include all trabecular tissue.

(d) Inner flap. This was as thin as possible and always $3 \times 3 \mathrm{~mm}$, so that about $1 \mathrm{~mm}$ was left for perfect closure and to prevent inadvertent cyclodialysis. The direction of dissection was from posterior to anterior after mapping out the course. A blade fragment was used, the sharp edge for cutting and the blunt edge for detaching ciliary 
body from scleral spur. In this way any cyclodialysis was avoided except for the excised area. The flap was excised at the anterior level of the superficial flap by the blade and sent for histopathological study.

(e) Iridectomy. The iris was abscissed in the horizontal axis with a medial and lateral pull, so

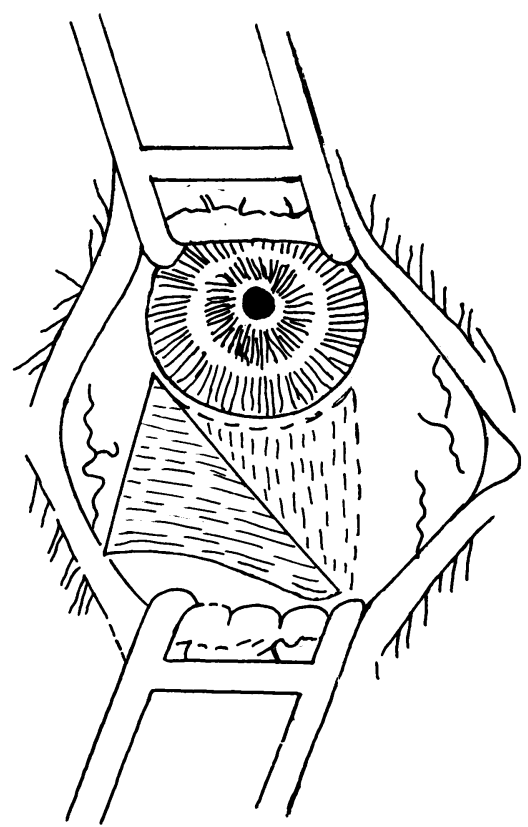

Fig. I Triangular conjunctiva-Tenon's flap reflected

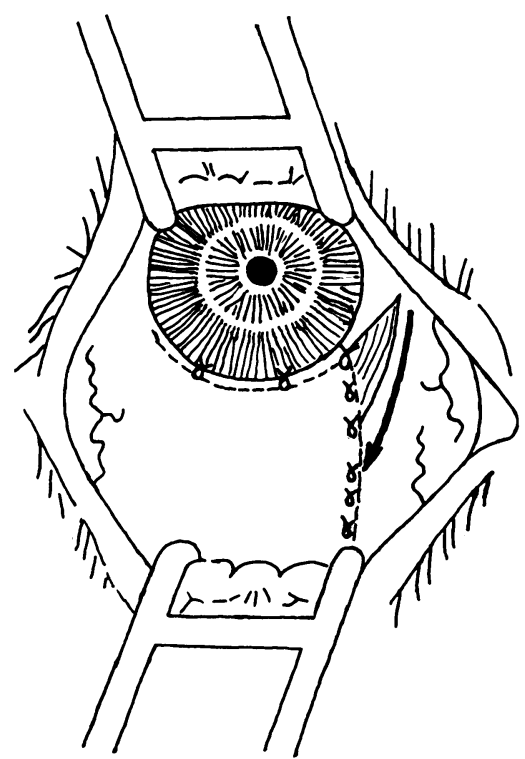

Fig. 2 Conjunctiva-Tenon's flap sutured
Table 4 Control of intraocular pressure

\begin{tabular}{lcc}
\hline IOP applanation & Eyes & Percentage \\
\hline $20 \mathrm{mmHg}$ or less & 106 & 95.4 \\
Above $20 \mathrm{mmHg}$ & 5 & 4.6 \\
\hline
\end{tabular}

Table 5 Postoperative intraocular pressure in 111 eyes

\begin{tabular}{lcc}
\hline IOP applanation & Eyes & Percentage \\
\hline 35 to $21 \mathrm{mmHg}$ & 5 & $4 \cdot 6$ \\
20 to $14 \mathrm{mmHg}$ & 85 & $76 \cdot 5$ \\
13 to $8 \mathrm{mmHg}$ & 17 & $15 \cdot 3$ \\
Below $8 \mathrm{mmHg}$ & 4 & $3 \cdot 6$
\end{tabular}

that a widely based peripheral iridectomy resulted. Pilocarpine $2 \%$ drops were instilled immediately after iridectomy. No iris repositor was used.

$(f)$ Suturing. Seven to 12 sutures are applied, the number depending on the size of the superficial scleral flap. A fine absorbable suture was used $(7 / 0,8 / 0$ Vicryl or $8 / 0$ virgin silk when Vicryl was not available). The anterior 2 sutures at the corneal end are important, and perfect apposition is aimed at. The conjunctiva is sutured as described earlier.

\section{Results}

The criterion of success in this study was reduction and maintenance of IOP below $20 \mathrm{mmHg}$ (applanation). This was achieved during the period of observation in 106 eyes $(95.4 \%)$. In 5 eyes of 4 patients the pressure remained in the range of 21 to $35 \mathrm{mmHg}$, and these patients were prescribed antiglaucoma drops for maintenance. However, the pressure was never below $21 \mathrm{mmHg}$ except when acetazolamide was added to the regimen.

The visual results were also satisfactory, maintaining the status quo or a line or part of a line less (Tables 4 and 5). It is interesting to note that of those in the PL/CF to $6 / 60$ group no one lost any further vision.

THE BLEB

The beginning of a bleb was seen on the first day in some cases, by third day in most, and in all by the fifth day. On the first weekly visit every case had a well protected flat bleb extending posteriorly. The blebs in those cases with the triangular conjunctivoTenon's flaps were fleshy and congested. Some of these proceeded to some encroachment on to the cornea and thin-walled honeycombing along with the flat posterior blebs in a 6-month period. Thinwalled areas were seen in a few cases anteriorly over 
suture sites in the limbal based conjunctivo-Tenon's cover also. In 1 eye there was no visible bleb when seen at 19 months, with well maintained IOP.

Gonioscopy showed peripheral anterior synechiae of one or both pillars of iridectomy in 14 eyes $(12.6 \%)$ (Table 6$)$. This did not in any way affect bleb formation or control of IOP. The rest of the angle showed no changes.

\section{COMPLICATIONS}

There were no significant complications during or after the operation, nor were complications observed during the period of observation. The minimal complications are shown in Table 7. The one shallow chamber reformed spontaneously on the third day. It was not possible to break the posterior synechiae by medical means. The 1 case of postoperative ocular hypertension was controlled by acetazolamide, phenylbutazone, and atropine and steroid drops, and no further complications occurred in that eye during the observation period.

\section{Discussion}

Follow-up of patients is difficult in these areas. However, it was possible to follow up $71 \%$ patients for a minimum period of 6 months and a maximum of 19 months. The decision to operate on nearly all these patients was governed by the near impossibility of maintaining them on a medical regimen even though the greatest number of eyes with glaucoma

Table 6 Thin-walled blebs and honeycombing

\begin{tabular}{llc}
\hline Nature and site of thin blebs & Eye/total & Percentage \\
\hline $\begin{array}{l}\text { Anteriorly over suture sites in limbal } \\
\text { based conjunctivo-Tenon's cover }\end{array}$ & $5 / 68$ & $7 \cdot 35$ \\
$\begin{array}{l}\text { Corneal encroachment and honey- } \\
\text { combing in triangular fornix-based } \\
\text { flap }\end{array}$ & $10 / 43$ & 23.03 \\
\hline
\end{tabular}

Table 7 Complications

\begin{tabular}{lll}
\hline Nature of complication & Eyes & Percentage \\
\hline Conjunctival buttonholing & 1 & 0.9 \\
$\begin{array}{l}\text { Shallow chamber } \\
\text { Hyphaema }\end{array}$ & 1 & 0.9 \\
$\begin{array}{l}\text { Posterior synechiae at pupil adjacent to } \\
\text { peripheral iridectomy }\end{array}$ & 3 & 3.6 \\
$\begin{array}{l}\text { Peripheral anterior synechiae of pillars of } \\
\text { iridectomy }\end{array}$ & 14 & 12.6 \\
$\begin{array}{l}\text { Increased IOP in the immediate postoperative } \\
\text { period }\end{array}$ & 1 & 0.9 \\
$\begin{array}{l}\text { Thin-walled blebs and corneal encroachment } \\
\text { Thing }\end{array}$ & 15 & 13.5 \\
\hline
\end{tabular}

have open angles (Keitzman, 1976; Sandford-Smith, 1978).

Whenever both eyes were affected, they were operated upon at the same time because: (a) theatre techniques and surgical refinements and anaesthesia have almost wholly abolished the very remote possibility of losing both eyes from surgical mishaps or infection; $(b)$ the patient is spared the duplication of all that is involved in 2 separate operations; and (c) there is greater utilisation of hospital beds.

In this series the large number of bilateral surgeries (104 eyes of 52 patients) means that the patients sought treatment late in the disease. However, these bilateral cases form the greater number in the follow-up also, presumably because the patients were keenly aware of the seriousness of bilateral disease, while those with only 1 eye affected became complacent after the successful treatment of that eye.

\section{CONTROL OF INTRAOCULAR PRESSURE}

Intraocular pressure was controlled below $20 \mathrm{mmHg}$ in $95.4 \%$ of eyes followed up. This has been achieved by following a standardised procedure and without recourse to accessory surgical means, such as excising Tenon's capsule (Welsh, 1972; Keitzman, 1976), non-suturing, loose suturing, or minimal suturing of the scleral flap (Welsh, 1972; Keitzman, 1976; Freedman et al., 1976; Fergusson and MacDonald, 1977; Sandford-Smith, 1978), excision of part of the scleral flap (sclerectomy), iris incarceration (Welsh, 1972), intentional cyclodialysis (Galin et al., 1975), cauterisation of posterior lip and the inner flap (Schimek and Williamson, 1977), very large resection of internal flap of the same measurements as the exterior flap (Keitzman, 1976; Sandford-Smith, 1978), and without recourse to medical measures such as high doses of systemic corticosteroids and/or subconjunctival depot steroids (Fergusson and MacDonald, 1977) and postoperative antiglaucoma medication in those cases not completely controlled (Freedman et al., 1976; Fergusson and MacDonald, 1977; David et al., 1977; Sandford-Smith, 1978). Before this study, such modifications to trabeculectomy procedures were undertaken because of the concept that filtration procedures often produced failures in the African patient (Welsh, 1970).

However, Cassady (1959) did not find sufficient statistical evidence in the literature for failure of filtration operations in the African and advocated a filtering procedure as the first choice in African patients, as did Haas (1958). Chatterjee and Ansari (1972) and David et al. (1977) achieved $79.2 \%$ and $91.6 \%$ success, respectively, with trabeculectomy without accessory procedures in the African. In this 
Table 8 Results of trabeculectomy in African glaucoma patients reported by various authors

\begin{tabular}{|c|c|c|}
\hline Author & Procedure & Percentage \\
\hline Welsh (1972) & With and without sclerectomy, excision of Tenon's capsule, iris incarceration & $79 \cdot 0$ \\
\hline Chatterjee and Ansari (1972) & Trabeculectomy alone & $79 \cdot 2$ \\
\hline Keitzman (1976) & $\begin{array}{l}\text { With excision of Tenon's capsule, excision of large internal flap, of same size and } \\
\text { external flap }\end{array}$ & $94 \cdot 0$ \\
\hline Freedman et al. (1976) & Non-suturing of scleral flap, postoperative antiglaucoma medication & $82 \cdot 0$ \\
\hline Fergusson and MacDonald (1977) & Loose approximation, high steroids, postoperative antiglaucoma medication & $84 \cdot 0$ \\
\hline David et al. (1977) & With and without antiglaucoma medication & $91 \cdot 0$ \\
\hline Sandford-Smith (1978) & $\begin{array}{l}\text { Non-suturing, minimum suturing, large excision of internal flap same size as external } \\
\text { flap }\end{array}$ & $87 \cdot 0$ \\
\hline Schimek and Williamson (1977) & Cautery of posterior lip and posteriorly of inner scleral layer & $83 \cdot 0$ \\
\hline Present authors & Standardised trabeculectomy only & $95 \cdot 4$ \\
\hline
\end{tabular}

study control of IOP was observed in $95.4 \%$ of the eyes after a standardised operation, and there was no postoperative antiglaucoma medication or steroids. The results of this study and those of various authors in African glaucoma population are shown in Table 8.

The reduction in pressures was substantial, and it had no particular relation to initial pressures or age or sex of patients. Even though a few patients had low pressures (below $8 \mathrm{mmHg}$ ), no complications were noted during the period of observation (Keitzman, 1976). The uncontrolled eyes were not amenable to topical antiglaucoma medication except when it was combined with acetazolamide.

The inclusion in this study of the group PL/CF to $6 / 60$ has shown (contrary to the usual practice at least so far as other filtering procedures are considered) that trabeculectomy is safe even in these types of cases when one is confronted with the problem of what is the most humane way of treating such cases (and there are many of them in this area). In this study the pressure was reduced in all except 1 patient ( 2 eyes), and no one's sight became worse after operation. It is hoped that they will maintain what vision they have for a longer period than they would have done if they had not been operated upon.

The cause of raised IOP in the immediate postoperative period in 1 case is not known. But it was quickly controlled by acetazolamide and phenylbutazone orally, and atropine and steroid drops topically. This patient has maintained an average of $20 \mathrm{mmHg}$ so far.

The immediate and long-term control of 1OP in this study may be due to the following factors. (1) Minimum postoperative inflammation and therefore no damage in the filtration angle. (2) Absence of shallow chamber, which is the most important single criterion (Schwartz and Anderson,
1974). This is achieved by the superficial scleral flap of more than two-thirds thickness which is sutured securely so that the anterior chamber has not been lost at any time (Rodriques et al., 1978). (3) Adequate filtration effected by a large superficial flap; a moderately large trabeculectomy $(3 \times 3 \mathrm{~mm})$, producing an adequate hiatus from the anterior chamber; adequate exposure of ciliary body beyond the scleral spur for easy egress of aqueous (Galin et al., 1975); a broad-based iridectomy, minimising the chances of synechiae; and the use of pilocarpine immediately after iridectomy to prevent peripheral anterior synechiae.

MECHANISM OF DRAINAGE

Trabeculectomy functions mainly as a filtration procedure (Ridgway, 1974; Galin et al., 1975). The mechanism of filtration may work in the following ways.

(1) Drainage into the conjunctivo-Tenon's space via (a) corneoscleral incisional sites (Kwitko, 1973), particularly through the corneal end, because the earliest sign of bleb formation is seen at this site; (b) the suture tracts, first by capillarity and later through the tracts (the sutures of superficial scleral flap are through-and-through and rest on the ledges of the posterior flap on 3 sides); (c) the exposed intrascleral drainage channels of the large superficial flap (Kwitko, 1973).

(2) Suprachoroidally (Kwitko, 1973), which must be minimum, because there is practically no cyclodialysis having a ledge of posterior scleral flap on 3 sides and because of the absence of choridal detachments and shallow chambers.

(3) Through the cut ends of Schlemm's canal, which is also probably minimal (Thyer and Wilson, 1972).

(4) A combination of all the above mechanisms. That trabeculectomy is a safe procedure with 
almost no complications (Watson and Barnett, 1975 ) is confirmed in this study also. The virtual absence of complications in this series of trabeculectomies may be attributed to the thick superficial scleral flap and its being sutured securely (Rodriques et al., 1978) and to the minimum of instrumentation.

Thus, the low incidence of hyphaema may be due to the selection of a site devoid of large vessels, particularly the perforating anterior ciliaries; the careful dissection of the posterior flap, avoiding injury to the ciliary body; avoiding injury to ciliary processes during iridectomy; immediate use of pilocarpine after iridectomy, which will keep the iris taut, compressing the vessels; the thick scleral flap, which gives pressure and protection; the secure suturing of the scleral flap (Freedman et al. (1976) had more hyphaema with unsutured flaps); the quick reformation of anterior chamber, keeping up an average IOP.

The near absence of shallow chambers must be directly attributed to the thick scleral flap and the secure closure of the same (Warmock, 1977; Rodriques et al., 1978).

The posterior synechiae of $2.7 \%$ may be because of the surgical trauma to the iris (these cases had the largest iridectomies) and the use of pilocarpine.

The absence of cataract from trabeculectomy in this series might be because of the minimal surgical trauma and inflammation; no loss of and quick reformation of anterior chamber; minimal instrumentation (pilocarpine is used to draw the iris into the chamber rather than its being reposited by an iris repositor); and the slow release of aqueous by a gradual iridectomy.

The formation of thin-walled honeycombing was seen in the semi-fornix-based triangular flaps and also the limbal-based conjunctivo-Tenon's flap. In both this occurred anteriorly at the corneal end of the corneoscleral incisions and over suture sites when virgin silk was used instead of absorbable sutures. This therefore can be avoided by meticulously suturing the corneal ends of the incisions and using absorbable sutures. In this series we have found that $8 / 0$ Vicryl is the best suture because of its fineness, manoeuvrability, knot security, and absorbability.

\section{FILTRATION BLEBS}

It was found that for a draining bleb it is not necessary in the African patient to excise the Tenon's capsule (Welsh, 1972; Keitzman, 1976). To do so would increase the risk of thin-walled blebs, with possible chances of injury and infection. Nor is it necessary to leave the scleral flap unsutured or minimally sutured (Freedman et al., 1976; Fergusson and MacDonald, 1977; Schimek and Williamson,
1977; Sandforth-Smith, 1978), to resort to combined sclerectomy or iris inclusion procedures (Welsh, 1972), to cauterise heavily the posterior lip and posterior lamella (Schimek and Williamson, 1977), or to administer systemic steroids to prevent fibrosis. Such procedures may increase the hazard of overdrainage, non-formation, and shallow chambers, which in turn would cause peripheral anterior synechiae and reduce the success rate.

The attempt in this study was to consider the African patient as any other glaucoma patient and to do the trabeculectomy in a standardised way, with care being taken to produce a well controlled drainage mechanism. With these aims all other forms of surgical treatment, as mentioned above, were avoided, and a thick superficial flap was fashioned and at the end of operation was securely sutured. These techniques have, in particular, avoided shallow chambers and produced controlled drainage consistently (Warmock, 1977; Rodriques et al., 1978). They have also prevented staphylomas (Spaeth and Rodriques, 1977) and infections or endophthalmitis (Freedman et al., 1978).

In this series a bleb, present sometimes on the first postoperative day and in all cases by the fifth day, possibly appears at the corneal end of the incisions, because in its earliest stages it is first noticed at these sites, perhaps in the same way as some filtration occurs after cataract incisions (Swan and Campbell, 1964). It is noteworthy that thinwalled blebs over sutures and in triangular conjunctivo-Tenon's flaps occurred at these anterior corneal incisional sites. Because of this, it is important to suture these anterior corneal incisions with special care.

The presence of a bleb was always associated with a well controlled IOP except in 1 eye with well controlled IOP in which no visible bleb was seen 19 months after operation (Ridgway et al., 1972; Freedman et al., 1976). The corneal encroachment with the triangular flaps may be prevented by more careful suturing at the limbus (Table 9).

It is not necessary to identify the Schlemm's canal or trabecular tissue and excise it for a successful trabeculectomy (Schwartz and Anderson, 1974; Galin et al., 1975). Histopathological study has shown $85 \%$ identification of Schlemm's canal and/or trabecular tissue.

\section{MAGNIFICATION IN TRABECULECTOMY}

Trabeculectomy has been made possible because of the more widespread use of the operating microscope, and the results from microsurgery of trabeculectomy are excellent in the hands of surgeons who are using the operating microscope routinely for most ophthalmic surgery. However, microsurgery 
Table 9 Advantages and disadvantages of the two types of conjunctivo-Tenon's faps

\begin{tabular}{|c|c|c|}
\hline & Advantages & Disadvantages \\
\hline \multirow[t]{2}{*}{ 1. Classical limbal based } & $\begin{array}{l}\text { 1. Blebs are well contained and never } \\
\text { encroach on the cornea }\end{array}$ & $\begin{array}{l}\text { 1. Buttonholing and tearing, especially in older patients } \\
\text { with thin conjunctiva }\end{array}$ \\
\hline & 2. Closure easier and secure & $\begin{array}{l}\text { 2. The reflected flap over the cornea precludes constant } \\
\text { view of superior cornea and pupil }\end{array}$ \\
\hline \multirow[t]{2}{*}{ 2. Triangular semi-fornix based } & 1. No buttonholing or tearing & 1. Suturing has to be more meticulous \\
\hline & $\begin{array}{l}\text { 2. Perfect exposure of operative area and } \\
\text { view of whole chamber and pupil }\end{array}$ & $\begin{array}{l}\text { 2. A tendency for the bleb to encroach on cornea and } \\
\text { thinning at these sites }\end{array}$ \\
\hline
\end{tabular}

However, the surgical results were equal with both types of conjunctivo-Tenon's flaps

in the hands of the occasional microscopist is not good enough. Advantageous as it is, the operating microscope is not essential for trabeculectomy. A magnification 2.5 times is sufficient for a properly and carefully executed trabeculectomy, as shown by this study, in which an operating loupe of 2.5 times was routinely used with excellent results. This means that trabeculectomy is within the capacity of the average ophthalmic surgeon to the great benefit of glaucoma sufferers, for the operation has proved to be the method of choice par excellence in the surgical management of glaucoma in both the African and the white races (Ridgway et al., 1972; Freedman et al., 1976; David et al., 1977).

\section{Conclusions}

The high rates of success and virtual absence of complications in this series of cases indicate that trabeculectomy functions as well in African patients with glaucoma as in the white races or even better. Trabeculectomy should be the method of choice in the surgical management of open-angle glaucoma irrespective of the patient's race.

We are grateful for the co-operation extended to us by the consultants, residents, nursing, and secretarial staff of the Guinness Ophthalmic Unit.

\section{References}

Becker, B. (1958). Quoted by Boyd, B. F. Highlights of Ophthalmology, 1, 201-209.

Cairns, J. E. (1969). Trabeculectomy for chronic simple open angle glaucoma. Transactions of the Ophthalmological Societies of the United Kingdom, 89, 481-490.

Cassady, J. R. (1959). Results of iridencleisis in Negro and white races. Archives of Ophthalmology, 62, 239-241.

Chatterjee, S., and Ansari, M. W. (1972). Microsurgical trabeculectomy in Ghana. British Journal of Ophthalmology, 56, 783-787.

David, R., Freeman, J., and Luntz, M. H. (1977). Comparative study of Watson's and Cairn's trabeculectomies in a black population with open angle glaucoma. British Journal of Ophthalmology, 61, 117-119.

Fergusson, J. C., and MacDonald, R. (1977). Trabeculectomy in blacks-a two year follow up. Ophthalmic surgery, 8, 41-43.

Freedman, J., Shen, E., and Ahrens, M. (1976). Trabeculec- tomy in a black American population. British Journal of Ophthalmology, 60, 573-574.

Freedman, J., Gupta, M., and Bunke, A. (1978). Endophthalmitis after trabeculectomy. Archives of Ophthalmology, 96, 1017-1018.

Galin, M. A., Bounik, V., and Robbins, R. M. (1975). Surgical landmarks in trabecular surgery. American Journal of Ophthalinology, 80, 696-701.

Haas, J. S. (1958). Quoted by Boyd, B. F., Highlights of Ophthalmology, 1, 201-209.

Iliff, C. E. (1944). Surgical control of glaucoma in the negro. American Journal of Ophthalmology, 27, 731-738.

Keitzman, B. (1976). Glaucoma surgery in Nigerian eyesa five-year study. Ophthalmic Surgery, 7, 52-58.

Kwitko, M. L. (1973). Glaucoma in Infants and Children, vol. 1, p. 582. Appleton Century-Crofts: New York.

Ridgway, A. E. A. (1974). Trabeculectomy, a follow-up study. British Journal of Ophthalmology, 48, 680-686.

Ridgway, A. E. A., Rubinstein, K., and Smith, V. H. (1972). Trabeculectomy (a study of 86 cases). British Journal of Ophthalmology, 56, 511-516.

Rodriques, M. M., Spaeth, G. L., Sivalingam, E., and Weinreb, S. (1978). Value of trabeculectomy specimens in glaucoma. Ophthalmic Surgery, 9, 29-38.

Sandford-Smith, J. H. (1978). The surgical treatment of open angle glaucoma in Nigeria. British Journal of Ophthalmology, 62, 283-286.

Schimek, R. A., and Williamson, W. R. (1977). Trabeculectomy with cautery. Ophthalmic Surgery, 8, 35-39.

Schwartz, A. L., and Anderson, D. R. (1974). Trabecular surgery. Archives of Ophthalmology, 92, 134-138.

Spaeth, G. L., and Rodriques, M. M. (1977). Staphyloma as a late complication of trabeculectomy. Ophthalmic Surgery, 8, 81-85.

Stocker, F. W. (1945). Response of chronic simple glaucoma to treatment with cyclodiathermy puncture. Archives of Ophthalmology, 34, 181-186.

Swan, K. C., and Campbell, W. L. (1964). Unintentional filtration after cataract surgery. Archives of Ophthalmology, 71, 43-49.

Thyer, H. W., and Wilson, P. (1972). Trabeculectomy. British Journal of Ophthalmology, 56, 37-40.

Warmock, D. C. (1977). Trabeculectomy. Transactions of the Ophthalmological Societies of the United Kingdom, 29, 85-87.

Watson, P. G. (1972). Surgery of the glaucomas. British Journal of Ophthalmology, 56, 299-306.

Watson, P. G., and Barnett, F. (1975). Effectiveness of trabeculectomy in glaucoma. American Journal of Ophthalmology, 79, 831-845.

Welsh, N. H. (1970). Failure of filtration operations in the African. British Journal of Ophthalmology, 54, 594-598.

Welsh, N. H. (1972). Trabeculectomy with fistula formation in the African. British Journal of Ophthalmology, 56, 32-36. 